\title{
An Overview of the U.S. National Plant Germplasm System's Exploration Program
}

\author{
Karen A. Williams ${ }^{1}$ \\ U.S. Department of Agriculture, Agricultural Research Service, National Germplasm Resources Laboratory, Plant \\ Exchange Office, 10300 Baltimore Avenue, Beltsville, MD 20705-2350
}

Additional index words. plant genetic resources, plant exploration, Convention on Biological Diversity, geographic information systems

\begin{abstract}
The Plant Exploration Program was established by USDA in 1898, several decades before the emergence of the US National Plant Germplasm System (NPGS), and continues to support international and domestic plant explorations for germplasm acquisition. These explorations are designed to fill collection gaps identified by the crop curators of the NPGS and the 40 Crop Germplasm Committees that counsel the NPGS. About 15 explorations are conducted annually under the auspices of this program. Although plant explorations to remote areas are often still the only means of acquiring unique new germplasm, the focus and methods applied by modern plant explorers have changed significantly in recent years in response to evolving germplasm needs and the new opportunities presented by recent technological advances. Modern explorations are characterized by the targeting of specific taxa and traits. New exploration techniques and tools, including geographic information systems and improved methods of data collection, are being applied to locate, document, and assess plant genetic diversity. During the past decade, legal obstacles faced by the Program have increased due to restrictive laws implemented in germplasm donor countries that exercise their national sovereignty over genetic resources, replacing the free and open access to genetic resources that prevailed before the ratification of the Convention on Biological Diversity in 1993. The NPGS has responded to these regulatory challenges with a flexible approach that includes nonmonetary benefit sharing and increased partnerships with host countries.
\end{abstract}

\section{History of the Program}

USDA established the Plant Exploration Program in 1898, several decades before the emergence of the U.S. National Plant Germplasm System (NPGS) (White et al., 1989). After more than 100 years of operation, the Program continues to support international and domestic plant explorations for germplasm acquisition. Planned and targeted collecting of plant genetic resources is recognized in the Global Plan of Action for the Conservation and Sustainable Utilization of Plant Genetic Resources for Food and Agriculture (FAO, 1996) as one of the 20 priority actions necessary to ensure the conservation and sustainable use of the world's plant genetic resources. Although plant explorations to remote areas are still the primary means of acquiring unique new germplasm, the focus and methods applied by modern plant explorers have changed significantly in recent years in response to evolving germplasm needs and the new opportunities presented by recent technological advances.

Both developed and developing countries rely heavily on production of non-indigenous crops to meet food needs (Palacios, 1998). Long before the establishment of USDA, the U.S. government recognized the importance of a diverse pool of introduced germplasm to developing the country's agricultural capacity and supported foreign explorations and germ-

Received for publication 20 May 2004. Accepted for publication 27 June 2004. I am grateful to Mark Widrlechner for organizing the symposium and providing useful comments on this paper. I also appreciate the helpful comments of Michael Dosmann. I would like to acknowledge Allan Stoner and Ned Garvey of the USDA-ARS National Germplasm Resources Laboratory for their support of the Plant Exploration Program. I would like to thank Judi duCellier for producing the map of explorations.

${ }^{1}$ To whom reprint requests should be addressed; e-mail kwilliams@ars-grin.gov. plasm exchange (Hodge and Erlanson, 1956; Hyland, 1977). When USDA was established by Congress as a separate unit of government in 1862 , one of its stated duties was "to procure, propagate, and distribute among the people new and valuable seeds and plants" (Department of Agriculture Organic Act of 1862). In 1897, efforts to introduce useful plants into the U.S. were concentrated in the USDA Section of Seed and Plant Introduction, and in 1898, the first appropriation was made to support plant exploration (Fairchild, 1939). This marked the beginning of the USDA Plant Exploration Program. Plant explorations have been conducted under the Program during every year since 1898, except from 1942 through 1945. All supported explorations in the first 50 years of the Program were foreign, but in the 1950s, the importance of native germplasm received more recognition and domestic explorations began (Burgess, 1971). From 1898 through 2003, 576 explorations were supported.

In the first half century of the Plant Exploration Program, a nationally coordinated plan to conserve the collected germplasm was lacking. Federal plant introduction gardens provided for the evaluation, propagation, and distribution of new germplasm (Hodge and Erlanson, 1956), but not long-term maintenance. In the late 1940s and early 1950s, the establishment of regional plant introduction stations through a partnership of USDA/ARS and the state agricultural experiment stations provided for secure maintenance of much of the introduced germplasm (Burgess, 1971). The National Seed Storage Laboratory was opened at Fort Collins, Colo., in 1958 for the long-term preservation of germplasm (Shands, 1995). In the 1970s, as a result of a combined federal and state effort, the NPGS arose as a national network of people and institutions responsible for the management of germplasm important to U.S. and world agriculture (National Research Council, 1991). Germplasm resulting from current USDA explorations is deposited with the NPGS site responsible for the specific plants collected.

\section{The Modern NPGS}

The NPGS today is coordinated by the USDA-ARS and involves cooperation with a number of federal, state, and private organizations. The 27 active sites of the NPGS acquire, maintain, regenerate, distribute, document, characterize, evaluate, and conduct research on seed, clonal, and genetic stock collections. The National Center for Genetic Resources Preservation (NCGRP, renamed in 2002 from the National Seed Storage Laboratory) provides long-term backup storage for the NPGS, as well as for some non-NPGS collections and foreign countries, and conducts research on preservation methodologies (Shands, 1995). All the NPGS sites are linked through the centralized Germplasm Resources Information Network (GRIN) database (USDA-ARS, National Genetic Resources Program, 2004), which contains passport, taxonomic, descriptor, observation, evaluation, and inventory data important for managers and curators responsible for the accessions (Table 1). The National Germplasm Resources Laboratory (NGRL) in Beltsville, Md., manages the GRIN database. Scientists in the germplasm user community can access GRIN online to view passport and evaluation data, make queries, and order germplasm. Another function of the NGRL is the facilitation of the activities of the 40 Crop Germplasm Committees (CGCs), composed of scientist users with expertise on a specific crop or group of crops, which provide advice to the NPGS on germplasm activities, including acquisition. The NGRL also administers the Plant Exploration Program.

The NPGS is one of the largest distributors of germplasm in the world. USDA maintains a policy of free and unrestricted exchange of 
Table 1. Summary of holdings in the USDA-ARS National Genetic Resources Program, 2004 (NPGS).

Number of families

Number of genera

Number of species

Total number of accessions

germplasm for research, breeding and education. For the years 1995 to 2003, an average of $>126,000$ samples of germplasm was distributed yearly to a total of 153 nations (M. Bohning, personal communication).

\section{The Current Program}

Among the genetic resources used by crop breeders and other researchers, traditional farmer varieties (landraces) and wild species related to crops are those usually targeted on plant explorations. In contrast to the broad goals of explorations conducted in the early years of the 20th century, modern NPGS plant explorations are mostly focused on specific taxa and traits. Wild species in the secondary or tertiary genepools of major crops are much more frequently emphasized than in the past, primarily resulting from the facilitation of their use in crop improvement by molecular genetics. Other wild species are targeted for their potential as new crops.

The objectives of NPGS explorations are numerous. Explorations are initiated to fill needs identified by NPGS crop curators, Crop Germplasm Committees, scientists in the Plant Exchange Office, and other researchers. An immediate need may exist for traits such as specific climatic adaptations or pest resistance that cannot be found in existing collections. Other gaps may be targeted with an eye toward future, as yet unknown, needs. Gaps are defined in a number of ways, including missing taxa, genotypes or alleles; under-represented environmental conditions or combinations of conditions; or inadequately covered portions of distribution. Another objective of some explorations is the rescue of germplasm desired for research purposes that is in immediate danger of genetic erosion or extinction.

The Plant Exchange Office (PEO) of the National Germplasm Resources Laboratory manages the NPGS Plant Exploration Program. Proposals based on detailed guidelines are accepted yearly and reviewed by a committee of NPGS personnel and other scientists. Endorsement of each proposal by the pertinent CGC (s) is required. In the rare case in which an exploration proposal targets a crop that is not included in the mandate of any CGC, another qualified expert may provide the endorsement.

The involvement of collaborators in the host country who are familiar with the local culture and the targeted plants is critical to the success of plant explorations. These hostcountry collaborators are typically involved from the early stages of planning of a NPGS exploration.

All plant explorations require careful planning and implementation (Engels et al., 1995). Explorers need extensive knowledge of the taxonomy, native ranges, ecological preferences, intraspecific variation, phenology, and human setting of the plants to be collected. The process of acquiring, organizing, and analyzing these data is called an ecogeographic survey (Maxted et al., 1995). Useful resources for conducting an ecogeographic survey include scientific literature, experts on the targeted taxa, previous germplasm collections, and herbarium specimens from international and local herbaria. In addition, maps of various types, including climatic, soil, topographic, vegetation, landuse, and socioeconomic, provide relevant data. Synthesis of the assembled information makes possible the informed selection of locations, timing, and approach for explorations.

Most plant species are rich in genetic variation, of which plant explorers can collect only a small fraction. In order to maximize the amount of variation sampled, sampling strategies must be carefully chosen. Defining an optimal strategy depends on a number of factors, including the biology of the targeted taxa and the objectives of the expedition. Choices to be made include the number and locations of sampling sites, the number of individual plants to sample at each site, how the individual plants are chosen for sampling, and the number and type of germplasm propagules to collect (Brown and Marshall, 1995). Sampling for a specific purpose, such as climatic adaptation, requires a modification of the methodology used to obtain a broad range of genetic variation.

Thorough documentation of germplasm collections is vital to effective conservation and utilization. Typically, all germplasm collected on NPGS explorations is documented with complete passport data, including collector numbers, locality data (including latitude, longitude, and elevation), associated vegetation, habitat description, plant characteristics, local uses, and other data as appropriate for specific purposes. Herbarium voucher specimens are made to document collections of wild taxa and are deposited with host-country herbaria and the U.S. National Arboretum Herbarium or another internationally recognized herbarium in the U.S. Specimens of associated pests and microsymbionts, such as rhizobium nodules, are sometimes collected and preserved.

Another important part of documentation is the production of reports, which are written after the conclusion of an exploration. Reports that include trip narrative, participants, itinerary, copies of permits, detailed passport data, and recommendations for subsequent explorations or other conservation activities are submitted for each exploration to the PEO, where they are maintained for future reference. Passport data are incorporated into the GRIN database when the collections are deposited in the NPGS. The incorporation of new accessions into the NPGS is monitored through the Plant Exploration Tracking System (PETS), a part of the GRIN database.

Protection against accidental introduction of diseases, insects, noxious weeds, and other organisms is an essential responsibility of the Program.NPGS plant explorers follow national plant quarantine laws and regulations administered through the USDA Animal and Plant Health Inspection Service (APHIS) and similar agencies in the host countries. All germplasm imported into the U.S. must be accompanied by a phytosanitary certificate from the country of origin, inspected by an APHIS inspector for evidence of insects, disease or weed contamination, and treated appropriately, when necessary. A protocol developed by the PEO is used by the Department of Homeland Security (DHS) for processing seeds and plants brought by NPGS plant explorers to U.S. Ports of Entry. APHIS regulations (Foreign Quarantine Notices, 1995) specify restrictions for importation of certain plant taxa of concern and the type of testing required for their release. Plants that have been determined to have a very high pest risk fall in the prohibited quarantine category and require processing at an appropriate quarantine facility after importation. Most accessions acquired through NPGS plant explorations that fall in this category undergo testing at the Plant Germplasm Quarantine Center in Beltsville. Limited capacity at the Center influences the number of accessions of prohibited plants that can be obtained on explorations.

A few noxious weeds are important components of germplasm collections. As provided by the Plant Protection Act (2000), APHIS regulates the introduction into the U.S. of nonindigenous invasive plants identified as potentially harmful to agriculture, navigation, natural resources, or public health. In the rare case in which a sample of a species in this category is collected on an NPGS exploration, an APHIS permit is required to maintain the collection and distribution to users is limited to those with the appropriate APHIS permit.

In addition to logistical considerations, many ethical issues are also relevant to plant explorations. NPGS foreign explorations follow a code of conduct, developed to ensure that ethical and conservation issues are carefully considered. As discussed in the following section on international issues, compliance with the tenets of the Convention on Biological Diversity (CBD) is a primary requisite for ethical conduct of explorations. In addition to authorization at the national level, various other types of permits, including protected area permits, provincial or other second-level administrative permits, private landowner permits, and permits from indigenous organizations, may also be required. Foreign explorations are always conducted in cooperation with scientists from the host country and collaboration with the national genetic resources programs is strongly encouraged. Germplasm obtained on explorations is shared by the NPGS and the host country. Explorers take precautions not to endanger the existence of wild populations from which they collect germplasm samples. They abide by the Convention on International Trade in Endangered Species of Wild Fauna and Flora (CITES, 1973), an international treaty that prohibits commercial trade in a list of endangered species and limits trade in species whose conservation status is of lesser, but still significant concern. The Code of Conduct developed for the USDA Plant Exploration 


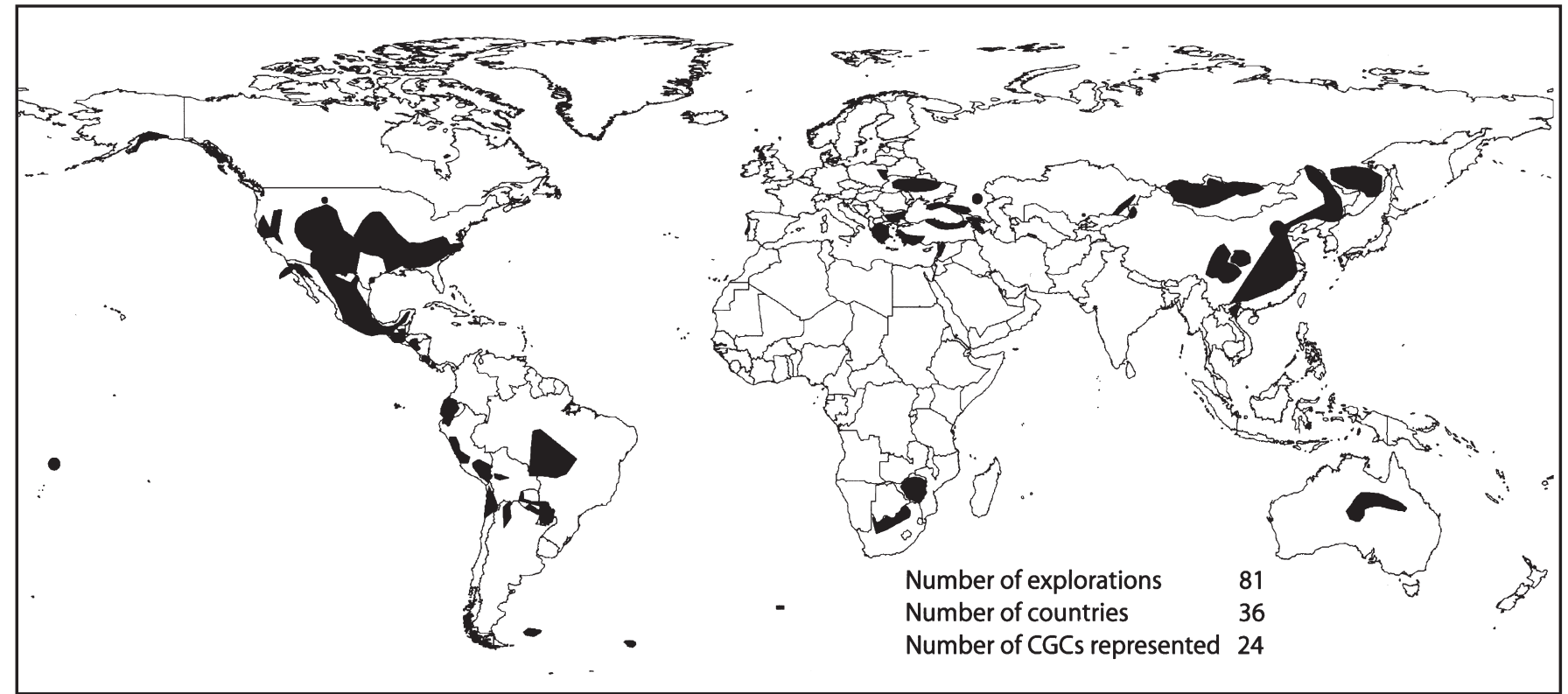

Program had a significant influence on the development of the FAO International Code of Conduct for Plant Germplasm Collecting and Transfer (FAO, 1993), now widely accepted around the world.

About 15 explorations are currently conducted each year under the auspices of this Program. From 1995 to 2002, 81 explorations were conducted in 36 different countries (Fig. 1). The number of different CGCs that provided the primary endorsement for the explorations reflects the diversity of crops targeted. In addition, landraces and wild relatives of many other crops that were secondary targets were collected on these explorations. Accessions collected on NPGS explorations account for about $20 \%$ of current germplasm acquisitions by the NPGS, with the remainder resulting from exchanges or donations.

\section{International Issues}

Most of the existing accessions in the NPGS and the world's other major genebanks were obtained during a time when genetic resources were considered the common heritage of humankind (FAO, 1983) and available without restrictions. During the past decade, the international climate for germplasm exchange has changed dramatically. Before 1993, free and open access to plant genetic resources prevailed as the global norm for germplasm exchange. Plant genetic resources could be readily collected and sent from one country to another in conformance with phytosanitary regulations. Collecting permits were required in some countries, but were typically obtainable with relative ease. In 1993, the CBD (1992), an international treaty dealing with the conservation and sustainable use of biological diversity, and the sharing of benefits arising from the use of genetic resources, became international law. The CBD recognizes the sovereign rights of nations over their genetic resources and provides that access to them is subject to prior informed consent from the national government. Access to genetic resources must also be based on mutually agreed terms on the sharing of benefits derived from their use or commercialization. The CBD has now been ratified by 187 countries and the European Union. Only seven countries in the world, including the United States, are not parties to the CBD. Although the U.S. is not a party, the U.S government recognizes the CBD as an international framework to facilitate access and ensure equitable sharing of benefits, and continues to contribute expertise to ongoing meetings of the CBD Conference of the Parties. A U.S. State Department Web page (U.S. State Department, 2003) provides guidance on complying with access and benefit sharing rules to U.S. researchers collecting genetic resources in other countries. The implementation of the CBD has presented considerable challenges for governments in countries seeking to regulate genetic resources under their jurisdiction, as well as for the governments and researchers of countries desiring access to foreign genetic resources.

Changes in international regulation of access have had a significant effect on the NPGS Plant Exploration Program. Since the CBD took effect in 1993, laws have been implemented in many germplasm donor countries exercising their national sovereignty over genetic resources and replacing the free and open access that

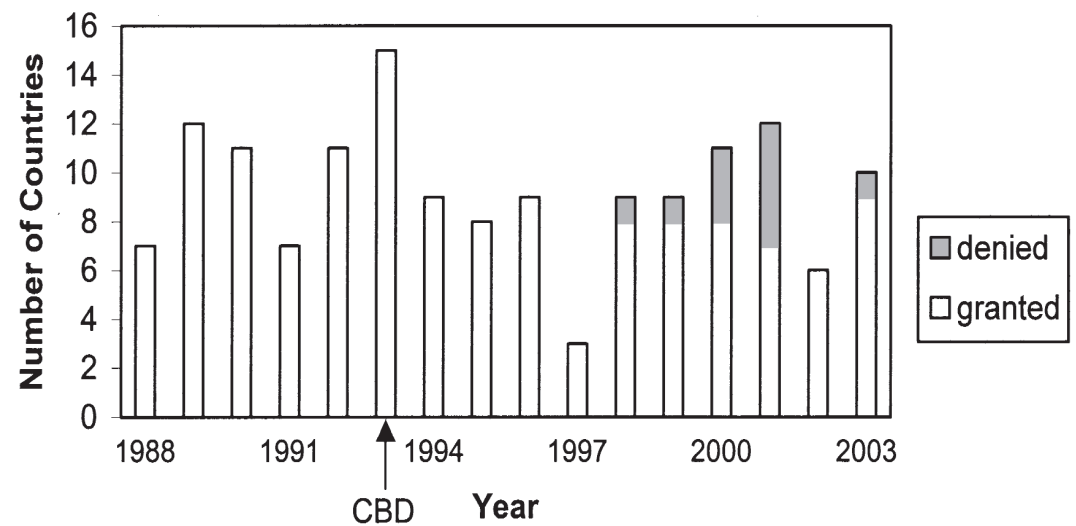

Fig. 2. Results of requests to foreign governments for access to germplasm for NPGS plant explorations, 1988-2003. prevailed previously. After a lag time during which countries were implementing their laws, instances of refusal or inability of foreign governments to process USDA requests for access increased (Fig. 2). Some countries are having difficulty implementing their laws on access, which sometimes results in their not being able to process applications. Authorities in some countries request restrictions on use or distribution of germplasm from explorations that are not consistent with USDA policies, while authorities in other countries simply do not respond to access requests. Reapplications in subsequent years are not made by USDA -ARS to countries in which experience has shown that mutually acceptable terms cannot be reached.

For explorations supported through the Program, the PEO either directly handles or closely coordinates contacts with national authorities in foreign governments to obtain prior informed consent.Each request for prior informed consent for an exploration includes information on target genetic resources, participants and their institutional affiliations, dates, work plan, location, intended use of germplasm and transfers to third parties, and benefit sharing arrangements. The Bonn Guidelines onAccess to Genetic Resources and Fair and Equitable Sharing of the Benefits 
Arising out of their Utilization (Convention on Biological Diversity Conference of the Parties, 2001) provide information on the steps in the process to obtain prior informed consent and determine appropriate benefit sharing.

Future access to some foreign genetic resources will be affected by another international agreement that recognizes the rights of nations to control access to genetic resources and to share in the benefits of using genetic resources. The International Treaty on Plant Genetic Resources for Food and Agriculture (IT) (FAO, 2001), which was adopted by the Conference of the UN Food and Agriculture Organization in November 2001, became international law on 29 June 2004. Although the IT does not govern direct access to germplasm in situ, it covers germplasm of any of the 64 crops and forages listed in the IT after they are collected and deposited in national or international genebanks.

\section{Benefit Sharing}

The NPGS has responded to the recent regulatory challenges with a flexible approach that includes nonmonetary benefit sharing and increased partnerships with host countries (Williams, 1998). The provisions on access and benefit sharing in the CBD were a response to concerns by some countries that they have not shared equitably in the benefits from use of genetic resources originating from within their borders, a perception that has been intensified by the increasing application of intellectual property rights to plant varieties and biotechnological inventions. Monetary benefits, such as payment of royalties, have often been at the center of discussions on benefit sharing, while important nonmonetary in-kind benefits have gone unrecognized or under-appreciated (Raymond and Fowler, 2001). The diverse objectives and indefinite time frame that characterize use of germplasm collected under the program make monetary remuneration impractical and less suitable than other forms of benefits.

Past NPGS explorations have provided various forms of nonmonetary benefits to the host country, such as paying the travel and equipment costs of the exploration, sharing half of the collected germplasm, deposition of herbarium specimens in the host country, strengthening of professional ties, transfer of information and technology, and collaboration in publication of research results. In addition, germplasm collected on NPGS plant explorations and conserved in the NPGS collections has always been available for repatriation to the donor country if it is lost there. Today, additional nonmonetary benefits may be associated with plant explorations when mutually agreed upon by USDA-ARS and the host country partners and authorities. The benefit-sharing approach taken by the NPGS is based on the premise that the additional support should contribute to the conservation of plant genetic resources in the host country, preferably by strengthening the capacity of its national plant genetic resources program. Such benefits include training of host-country scientists, projects to increase and evaluate germplasm, and support to in situ conservation. Nonmonetary benefits most likely will exceed the value of monetary benefits that might eventually result from any commercial gains derived from use of the germplasm acquired.

NPGS nonmonetary benefit-sharing arrangements over the past decade have involved a number of different activities. The first significant activity of this type was associated with explorations for peanut landraces in Ecuador in 1995 and 1996 (Williams and Williams, 2001). Peanut germplasm collected on those explorations was increased and characterized at the INIAP Experiment Station in Portoviejo, Ecuador under contract to the USDA, replacing work that would ordinarily have been done in the U.S.A U.S. peanut breeder went to Ecuador to train the Ecuadorians in peanut characterization methods using the U.S. Peanut Descriptors (Pittman, 1995).Explorations for Capsicum and Arachis in Paraguay between 1998 and 2002 have been associated with a number of benefits to Paraguay (International Plant Genetic Resources Institute, 1998; Williams, 1998; Williams and Williams, 2001). These benefits have included long-term storage of collected germplasm at the USDA NCGRP on behalf of Paraguay; increase and characterization of collected germplasm in Paraguay and associated training; sponsorship of Paraguayan scientists at international scientific meetings; purchase of small equipment; training in Geographic Information System (GIS) technology; and an inventory and analysis of twenty genera of native crop wild relatives to support in situ conservation efforts. In association with two explorations for cotton germplasm in Mexico, technical support has been provided to a National Institute of Forestry, Agricultural and Animal Research nursery for wild cotton. Other examples of benefit sharing projects associated with NPGS plant explorations include establishment of a field collection of collected apple germplasm in Turkey, a visit of collaborating Chinese forage scientists to U.S. laboratories, and training of a Honduran scientist in bean breeding and pathology.

In addition, NPGS explorers and the PEO have collaborated with two other USDA agencies, the Foreign Agricultural Service (FAS) and the Cooperative State Research, Education, and Extension Service (CSREES), to develop broad collaborative programs that include plant exploration as a component. These collaborations are able to provide greater nonmonetary benefits to germplasm donor countries than the limited Plant Exploration funds. Collaboration with the FAS Commodities Exchange Program supported the renovation of the former Central Asian Genebank in Uzbekistan and the collection, evaluation and storage of germplasm in Bangladesh and Sri Lanka. Collaboration with the CSREES Marketing Assistance Program provided training on ex situ germplasm documentation to Armenian scientists in the U.S. and supported equipment acquisition for the plant genetic resources program in Armenia.

\section{New Technology}

New exploration tools and techniques, including GIS and improved methods of data collection, are being applied in the Program to locate, document, and assess plant genetic diversity. Global positioning system receivers are standard equipment for all NPGS explorations. Increasingly, GIS technology is being used to plan and guide explorations. If adequate data, including passport, characterization, and evaluation data are available, the potential for GIS to assist explorers is enormous. Considering that time and funds for fieldwork are limited, and suitable habitats are diminishing and more difficult to locate, GIS are welcome tools to increase the efficiency of plant explorations.

In planning, GIS can be enormously helpful in organizing and analyzing ecogeographic information. GIS can identify geographic areas that are likely to contain specific traits, taxa or habitats; highly diverse; complementary to other areas; under-represented in collections; or threatened with genetic erosion (Guarino et al. 2002).

In the field, GIS can be used as guides on where to collect, based on the specific interests of explorers. One recent example of the use of GIS is an NPGS exploration for crop wild relatives of alfalfa and other forage legume species in Kazakhstan (Greene et al., in press). GIS were used to identify climatic and soil conditions so that germplasm was collected from a diversity of ecogeographic zones. In Paraguay, GIS analysis was used to guide an NPGS exploration for a rare wild pepper species, Capsicum flexuosum, for which previous explorations had been unable to locate germplasm (Jarvis et al., in press). In that case, exact locations for collecting were identified by using a combination of three factors: climatic zones predicted to be suitable for the species by the software Floramap (Jones and Gladkov, 1999), forested areas indicated by land-cover maps, and road maps to limit search areas to accessible regions. Fieldwork using the GIS resulted in the location of five previously undocumented populations of the species, one of which was outside its known range.

\section{Followup to Plant Explorations}

After an exploration is completed, much follow-up remains for NPGS plant explorers to guarantee that collected germplasm will be conserved and available for use. Explorers need to make certain that germplasm along with the associated passport data is provided to the appropriate NPGS collection. Herbarium voucher specimens must be deposited with appropriate institutions. Plans for collaborative research with host-country scientists, including that identified as benefit sharing, must be implemented. Publications and reports, ideally written in collaboration with host-country scientists, should be used to disseminate information on collecting activities and the germplasm that was collected. Wide circulation of information will encourage study and use of the collections, which will help to sustain support for long-term conservation. In addition, data generated through study of the germplasm, when combined with passport data, will lead to a more thorough understanding of the genetic diversity within the genepool of the taxon or crop and its geographic distribution. 
This will allow for the identification of gaps still remaining in collections and provide the foundation for planning additional effective plant explorations to fill these gaps.

\section{Conclusions}

Germplasm collected on plant explorations today is our legacy for tomorrow. Although today's plant explorers have new technological tools to improve the effectiveness of field exploration, they face the unfamiliar challenges of regulatory restrictions. Plant explorers must meet these challenges with innovative approaches that demonstrate the advantages of international collaboration in the conservation of genetic resources, thus helping to ensure that the resources needed to sustain global agriculture in the 21 st century and beyond will be available for all humankind.

\section{Literature Cited}

Brown, A.H.D. and D.R. Marshall. 1995. A basic sampling strategy: theory and practice, p. 75-91. In: L. Guarino, V. Ramanatha Rao, and R. Reid (eds.). Collecting plant genetic diversity: Technical guidelines. CAB Intl., Wallingford, U.K.

Burgess, S. (ed.). 1971. The national program for conservation of crop germ plasm (a progress report on federal/state cooperation). University Printing Dept., Univ. Ga., Athens.

Convention on Biological Diversity. 1992. International legal materials 31:822-841.

Convention on Biological Diversity Conference of the Parties. 2001. Bonn guidelines on access to genetic resources and fair and equitable sharing of the benefits arising out of their utilization. 10 Feb. 2004. http://www.biodiv.org.decisions/defgault.aspx ?m=cop06\&d=24.

Convention on International Trade in Endangered Species of Wild Fauna and Flora (CITES). 3 Mar. 1973. 993 U.N.T.S. 243 (entered into force 1 July 1975).

Department of Agriculture Organic Act of 1862.12
Stat. 387; 7 U.S.C. 2201.

Engels, J.M.M., R.K. Arora, and L. Guarino. 1995. An introduction to plant germplasm exploration and collecting: planning, methods and procedures, follow-up, p. 31-63. In: Guarino, L., V. R. Rao, and R. Reid (eds.). Collecting plant genetic diversity: Technical guidelines. $\mathrm{CAB}$ Intl., Wallingford, U.K.

Fairchild, D. 1939. The world was my garden. Charles Scribner's Sons, New York.

FAO. 1983. International undertaking on plant genetic resources. FAO, Rome.

FAO. 1993. International code of conduct for plant germplasm collecting and transfer. FAO, Rome.

FAO. 1996. Global plan of action for the conservation and sustainable utilization of plant genetic resources for food and agriculture. FAO, Rome.

FAO. 2001. International treaty on plant genetic resources for food and agriculture. FAO, Rome.

Foreign Quarantine Notices. 1995. Code of Federal Regulations. Title 7, Pt. 319.37.

Greene, S.L., R. Hannan, A.Afonin, N.I. Dzyubenko, and A. Khusainov. Collecting wild crop relatives in the northwestern steppes of Kazakhstan. Plant Genet. Resour. Nwsl. (in press).

Guarino, L., A. Jarvis, R.J. Hijmans, and N. Maxted. 2002. Geographical information systems (GIS) and the conservation and use of plant genetic resources, p. 387-404. In: J.M.M Engels, V. Ramanatha Rao, A.H.D. Brown, and M.T. Jackson (eds.). Managing plant genetic diversity. CAB Intl., Wallingford. U.K.

Hodge, W.H. and C. O. Erlanson. 1956. Federal plant introduction-A review. Econ. Bot. 10:299-334.

Hyland, H. L. 1977. History of plant introduction in the United States. Environ. Rev. 4:26-33.

International Plant Genetic Resources Institute. 1998. Picking peppers in Paraguay: A lesson in international cooperation, p. 28. In: R. Raymond (ed.). Geneflow. Intl. Plant Genet. Resour.Inst., Rome.

Jarvis, A., K. Williams, D. Williams, L. Guarino, P.J. Caballero, and G. Mottram. Use of GIS for prioritizing a collecting mission for a rare wild pepper (Capsicum flexuosum Sendtn.) in Paraguay. Genet. Res. Crop Evol. (in press).
Jones, P.G. and A. Gladkov. 1999. Floramap: A computer tool for the distribution of plants and other organisms in the wild. CIAT, Cali, Colombia.

Maxted, N., M.W. van Slageren, and J.R. Rihan. 1995. Ecogeographic surveys, p. 255-285. In: L. Guarino, V. Ramanatha Rao, and R. Reid (eds.). Collecting plant genetic diversity: Technical guidelines. CAB Intl., Wallingford, U.K.

National Research Council. 1991. Managing global genetic resources. U.S. Natl. Plant Germplasm System, Natl. Acad. Sci., Wash., D.C.

Palacios, X.F. 1998. Contribution to the estimation of countries' interdependence in the area of plant genetic resources. Background Study Paper 7 Rev. 1. FAO Comm. Genet. Resour. Food Agr., Rome.

Pittman, R.N. (ed.). 1995. United States peanut descriptors. USDA-ARS-132.

Plant Protection Act. 2000. U.S. Code. Title 7, Sec. 7701-7772.

Raymond, R. and C. Fowler. 2001. Sharing the nonmonetary benefits of agricultural biodiversity. Issues in Genetic Resources No. 5, Sept. 2001. Intl. Plant Genet. Resour. Inst., Rome.

Shands, H.L. 1995. The U.S. National Plant Germplasm System. Can. J. Plant Sci. 75:9-15.

USDA, ARS, National Genetic Resources Program. Germplasm Resources Information Network -(GRIN). 30 Mar. 2004. National Germplasm Resources Laboratory, Beltsville, Md. http:// www.ars-grin.gov/npgs/searchgrin.html.

U.S. State Department. 2003. Information for U.S. government funded researchers collecting in situ genetic resources outside the United States. 30 March 2004. http://www.state.gov/g/oes/rls/ or/25962.html.

White, G.A., H.L. Shands, and G.R. Lovell. 1989. History and operation of the National Plant Germplasm System. Plant Breed. Rev. 7:5-56.

Williams, K.A. 1998. Plant Exchange Office leads way in establishing nonmonetary benefit-sharing regimes. Diversity 14(3-4):23-24.

Williams, K.A. and D.E. Williams. 2001. Evolving political issues affecting international exchange of Arachis genetic resources. Peanut Sci. 28:132-135. 